\title{
Variação do segmento /d/ no contexto /ndo/: efeitos prosódicos e de leitura
}

\section{Variation of the segment /d/ in /ndo/: prosodic and reading effects}

\author{
Paloma Batista Cardoso 1 \\ Bruno Felipe Marques Pinheiro ${ }^{2}$ \\ Lucas Santos Silva ${ }^{2}$
}

DOI: $10.28998 / 2317-9945.2019 n 63 p 174-191$

\begin{abstract}
Resumo
O apagamento do /d/ no segmento /ndo/ resulta da assimilação do fonema /d/ pelo /n/, levando a realizaçoes como / cantando/ > / cantano/, que parecem se comportar como um marcador na fala (LABOV, 1972), sensivel ao contexto de formalidade e escolarização. Neste texto, mostramos o comportamento deste fenômeno na leitura, aqui tomada como ação que ativa na memória do leitor informacõos fonológicas características à sua comunidade de fala. A análise é feita com um corpus constituído pela leitura em voz. alta de 20 estudantes que residem em Aracaju, de nivel médio e superior. Os resultados apontam que o fenômeno é observável na leitura, mas, em ambientes monitorados, o segmento Indo/ tende a ser preservado.
\end{abstract}

Palavras-chave: Leitura. Gerúndio. Variação

\begin{abstract}
The deletion of $/ d /$ in the segment $/$ ndo/ is the result of the assimilation of the phoneme $/ d /$ by $/ n /$, leading to realizations such as / cantando/ > / cantano/, which seem to behave as a marker in speech (LABOV, 1972), susceptible to the context of formality and schooling. In this text we show how this phenomenon works in reading, here understood as an action that activates in the reader's memory distinctive phonological information of his/her speech community. The analysis was conducted based on a corpus constituted by the reading aloud performed by 20 students of high school and higher level who live in Aracaju. The results indicate that the phenomenon can be observed in reading, but in contexts where the subjects are monitored the segment / ndo/ tends to be preserved.
\end{abstract}

Keywords: Reading. Gerund. Variation

Recebido em: 19/06/2018.

Aceito em: 26/09/2018.

\footnotetext{
${ }^{1}$ Graduada em Letras Vernáculas pela Universidade Federal de Sergipe, membro do Grupo de Estudos em Linguagem, Interação e Sociedade - GELINS.

${ }^{2}$ Graduado em Letras Vernáculas pela Universidade Federal de Sergipe, membro do Grupo de Estudos em Linguagem, Interação e Sociedade - GELINS.
} 


\section{Considerações iniciais}

Estudos sociolinguísticos têm evidenciado a heterogeneidade linguística sistemática, relacionada às práticas de linguagem que circulam na sociedade (LABOV, 1972). Neste trabalho, consideramos a existência de variação linguística nas práticas de leitura em voz alta, assumindo que a leitura oralizada tem seu fundamento na língua falada, pois "a pronúncia de uma palavra apresentada visualmente envolve designar algum tipo de codificação acústica ou articulatória à sequência de letras em questão" (FORSTER; CHAMBERS, 1973, p. 632 apud COLTHEART, 2013, p. 24-25).

Machado (2018) destaca o reconhecimento da realização de traços sociolinguísticos variáveis na leitura em voz alta como indicadores para avaliar a proficiência do leitor. A relação entre variação linguística e leitura foi evidenciada por Labov e Baker (2003) que, a partir de um estudo desenvolvido com crianças das classes minoritárias, analisaram como a variação linguística influencia o processo de aprendizagem da leitura; e Bortoni-Ricardo (2004), que expôs a teoria dos contínuos de falares rurais e urbanos para trabalhar a influência das noções de erro e acerto no processo de ensino.

A leitura é uma atividade que demanda consciência sobre as unidades e os processos linguísticos, sejam eles semânticos, pragmáticos, gráficos ou fonológicos. Como afirma Coltheart (2013, p. 24), "ler é processar informações: transformar escrita em fala, ou escrita em significado. Qualquer pessoa que tenha aprendido a ler terá adquirido um sistema mental de processamento de informações capaz de realizar essas transformações". Uma dessas informações é a noção lexical e fonológica. Por isso, estabelece-se o seguinte questionamento: até que ponto os processos fonológicos sensíveis à avaliação social, como é a assimilação do /d/ em contexto /ndo/, é observável na leitura?

Hora e Aquino (2012), ao analisarem o apagamento da oclusiva dental /d/ no grupo /ndo/ na leitura de crianças, concluíram que todas as ocorrências de apagamento do /d/ aconteceram com a forma verbal no gerúndio, como também foi evidenciado nos estudos de Martins (2004) e Mollica (1998), para a fala. Não foram localizados estudos sobre o fenômeno com estudantes em níveis mais altos de escolarização, embora tenham sido encontrados estudos que mostram que a escolaridade do falante interfere na taxa de realização de apagamento (FREITAG; CARDOSO; PINHEIRO, no prelo).

É nesta perspectiva, da variação e leitura, sob o viés da sociolinguística variacionista que, neste artigo, investiga-se como se dá o apagamento da oclusiva dental /d/ em contextos /ndo/ na leitura em voz alta, entre estudantes do ensino médio e superior. O apagamento deste segmento é o resultado da assimilação do fonema /d/ pelo fonema /n/, o que ocasiona duas variantes: uma com a presença da oclusiva dental /d/ e outra com a ausência dela, a exemplo de /planejando/ > / planejano/.

Inicialmente, o fenômeno é contextualizado na perspectiva sociolinguística para a variação na fala; em seguida, o método é apresentado, e, por fim, os resultados da presente investigação são expostos em duas perspectivas: uma acústica e outra variacionista, com o objetivo de evidenciar o caráter de marcador sociolinguístico sensível ao contexto de formalidade concernente à queda ou manutenção do / $\mathrm{d} /$ na leitura. 


\section{Apagamento do /d/ em contextos /ndo/ no português brasileiro falado}

O fenômeno /ndo/ $>/$ no/ tem sido amplamente estudado no Português Brasileiro (MOLLICA; MATTOS, 1992; FERREIRA; TENANI; GONÇALVES, 2012; NASCIMENTO; ARAÚJO; CARVALHO, 2013; ALMEIDA; OLIVEIRA, 2017; entre outros), em diferentes variedades, sob perspectivas sociais, estruturais e acústicas.

Lucena e Vasconcelos (2007) analisaram, em uma variedade do Brejo Paraibano, o apagamento do /d/ em contexto / ndo/ em quatro classes de palavras: substantivo comum, conjunção, verbo no gerúndio e verbo no presente do indicativo. A pesquisa foi realizada com seis informantes de 16 a 25 anos, dos sexos feminino e masculino, universitários, que nasceram na região ou que nela residem desde os cinco anos.

Os autores constataram que, na realização do grupo /ndo/, o apagamento da oclusiva /d/ foi desfavorecido, pois apresentou um percentual de 32,5\%; contra $67 \%$ de manutenção. Isto sugere que a redução do gerúndio não é um fenômeno característico desse grupo de falantes, corroborando com a premissa de que falantes com maior nível de escolaridade tendem a não realizar o apagamento da referida consoante.

No que diz respeito ao apagamento do /d/, uma das hipóteses assumidas foi que esse fenômeno é mais recorrente entre as formas de gerúndio, o que de fato foi comprovado. Os autores explicam que "o apagamento do /d/ ocorre com maior frequência quando o grupo /ndo/ faz parte de um sufixo; por outro lado, quando ele ocorre dentro da palavra (raiz), a preservação da oclusiva dental /d/ será maior". (LUCENA; VASCONCELOS, 2007, p. 236). Tal assertiva justifica o alto percentual de não-apagamento da consoante entre conjunção e substantivo comum:

Figura 1: presença da oclusiva /d/ no grupo /ndo/. Fonte: Lucena e Vasconcelos (2007).

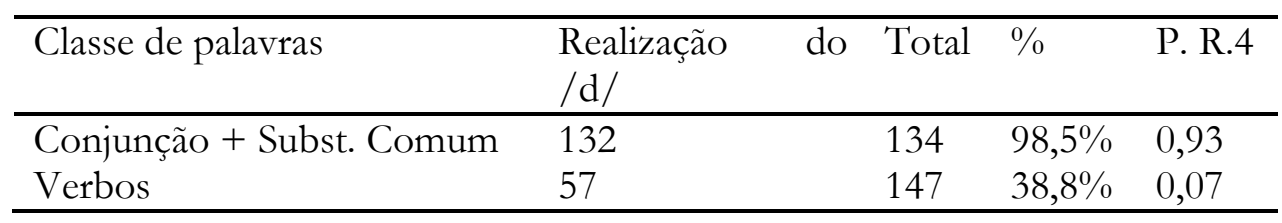

Já no falar de Maceió, Almeida e Oliveira (2017), a partir de entrevistas com 30 informantes, 15 homens e 15 mulheres, estratificados por sexo (feminino, masculino) e faixa-etária (18 a 30 anos, 40 a 55 e acima de 65), também atestaram este fato. De um total de 524 produções de formas de gerúndio, houve o apagamento em 219 (42\%).

Almeida e Oliveira (2017) apresentam como variáveis linguísticas estatisticamente significativas a extensão do vocábulo e o contexto fonético-fonológico. Os autores partiram do pressuposto de que quanto maior o item, maior a chance de apagamento do /d/. Esta hipótese foi confirmada, uma vez que as palavras polissílabas apresentaram um percentual de apagamento de 51,4\%; enquanto que as dissílabas, de 29,6\%. Em relação ao contexto fonético-fonológico seguinte, os resultados sinalizaram os contextos característicos de haplologia em que houve supressão das consoantes /t/, /n/, /d/ por influência das vogais, o que se mostrou bastante significativo, pois a taxa de supressão nesse contexto foi de $87,5 \%$.

Quanto aos fatores sociais, ainda sobre o estudo anterior, foram considerados faixa etária e gênero, sendo este último o único relevante. Os homens apresentaram maior 
percentual de apagamento (52\%), diferente das mulheres $(30,4 \%)$ o que, para os autores, corrobora a premissa de que mulheres tendem a evitar o uso de formas socialmente estigmatizadas.

Em trabalho realizado com dados do Atlas Linguístico do Brasil - Alib, Araújo e Aragão (2016) investigaram a redução do gerúndio nas nove capitais do Nordeste (Aracaju, Fortaleza, João Pessoa, Maceió, Natal, Recife, Salvador, São Luís e Teresina) e nas quatro capitais do Sudeste (São Paulo, Rio de Janeiro, Vitória e Belo Horizonte). Para tal, as autoras se valeram de um questionário fonético-fonológico, respondido por 104 informantes, sendo oito de cada localidade. A amostra do estudo foi estratificada em três variáveis: escolaridade, faixa etária e gênero.

No que diz respeito aos aspectos metodológicos, Araújo e Aragão (2016) chamam atenção para o fato de os dados terem sido obtidos a partir de um questionário, o que "contribui para que os informantes se mostrem cautelosos com as respostas dadas ao inquiridor" (2016, p. 8). Os resultados obtidos mostraram que, tanto no Sudeste quanto no Nordeste, a regra é a manutenção do /d/. Nas capitais do Sudeste, a porcentagem de apagamento foi de 15,20\%. Os grupos de fatores estatisticamente relevantes foram: sexo/gênero e escolaridade. Os homens favoreceram a ocorrência do fenômeno em análise, com uma realização de $27,7 \%$; enquanto que as mulheres apresentaram um comportamento conservador, apagando o /d/ em apenas 2,2\% das ocorrências.

Para as autoras, "este resultado confirma a tendência de que as mulheres preferem as formas linguísticas padrão e de prestígio, como mostram os primeiros estudos sociolinguísticos (LABOV, 1966, 2008; TRUDGILL, 1974; FISCHER, 1958 apud PAIVA, 2003)" (ARAÚJO; ARAGÃO, 2016, p. 10).

O Nordeste apresentou uma taxa de apagamento maior, em comparação à do Sudeste: nas capitais nordestinas, a ocorrência do fenômeno foi de 22,90\%. Os grupos de fatores relevantes também foram sexo/gênero e escolaridade. Nesta região, os homens também realizaram mais o apagamento do /d/, com uma ocorrência de 32,7\%, enquanto as mulheres realizaram o fenômeno em $13,2 \%$ dos casos.

Nas duas regiões, apesar da diferença entre os resultados, há um padrão: o da manutenção do /d/. Há também um padrão em relação à escolaridade: tanto no Sudeste quanto no Nordeste quanto maior a escolaridade, menor a ocorrência do apagamento. (ARAÚJO; ARAGÃO, 2016).

Ferreira, Tenani e Gonçalves (2012), ao analisarem o morfema de gerúndio em São José do Rio Preto e em seis cidades fronteiriças (Bady Bassit, Cedral, Guapiaçu, Ipiguá, Mirassol e Onda Verde), consideraram tanto aspectos estruturais quanto variacionistas.

Valendo-se de um experimento fonético, os autores mediram a percepção da ocorrência ou não do /d/ em contextos /ndo/ a partir do controle de três variáveis: conjugação verbal, regularidade/irregularidade morfológica do verbo e estrutura sintática. Foram construídas 24 sentenças, realizadas três vezes, cada uma, por três informantes do sexo/gênero feminino, totalizando 216 ocorrências da forma /ndo/.

Durante o teste de percepção, ouvintes-juízes foram orientados a indicar a presença ou ausência do /d/ em contextos de gerúndio. A presença dessa consoante é atestada pela inspeção acústica realizada com o 
PRAAT, que possibilita a adoção dos parâmetros de quantificação closura, burst, transição formântica e duração relativa do /d/; que, segundo Kent e Read (1992), dão pistas para caracterizar a presença da consoante (FERREIRA; TENAN; GONÇALVES, 2012, p. 172).

Os resultados do teste apontaram divergências entre a realização e a percepção do /d/ em apenas 12 ocorrências. Essas divergências dizem respeito à realização da consoante: houve casos em que ela foi percebida pelos ouvintes-juízes, mas não foram realizadas; e houve casos em que ela não foi realizada, mas percebida. Para os autores,

O fato de um segmento ser percebido como realizado não ser atestado por meio da inspeção acústica pode ser motivado pela percepção de algum parâmetro caracterizador da consoante [d]; no entanto, esse segmento pode, de fato, não ter sido produzido com todos os parâmetros suficientes para caracterizá-lo na inspeção acústica (FERREIRA; TENANI; GONÇALVES, 2012, p. 173).

A realização ou não do /d/ apontada nos testes evidencia que o apagamento dessa oclusiva é uma regra variável, ou seja, pode ou não ocorrer. Este fato é tomado pelos autores como justificativa para uma análise variacionista do fenômeno em questão. Eles partiram do pressuposto de que, assim como há fatores estruturais que possibilitam ou não a apagamento da consoante oclusiva, há também fatores sociais.

Os dados utilizados na análise variacionista foram coletados entre um grupo de informantes que constituem o banco de dados Iboruna, que possui amostra de comunidade (ou censo), e amostra de interação dialógica. $\mathrm{Na}$ pesquisa em questão, os autores utilizaram inquéritos da Amostra Censo, que foram estratificadas em: sexo/gênero (masculino/feminino); faixa etária (de 7 a 15 anos, de 16 a 25, de 26 a 35, de 36 a 55, mais de 55) e nível de escolaridade $\left(1^{\circ}\right.$ ciclo do ensino fundamental, $2^{\circ}$ ciclo do ensino fundamental, ensino médio e ensino superior). A partir dessas variantes sociais, foram selecionadas 76 amostras de fala com trechos em que havia narração de experiência pessoal.

Ao todo, houve 999 ocorrências de formas verbais no gerúndio. A taxa de aplicação do apagamento do /d/ foi de $72 \%$, o que evidencia que "o fenômeno é uma característica marcante da variedade falada em São José do Rio Preto, interior paulista (FERREIRA; TENANI; GONÇALVES, 2012, p. 178).

As variáveis estatisticamente mais relevantes para a aplicação da regra foram: faixa etária, escolaridade, sexo/gênero. Quanto à primeira, os informantes mais jovens favoreceram o apagamento do /d/ (figura 2). Os informantes mais velhos, por sua vez, desfavoreceram a aplicação da regra, o que, para os autores, indicaria uma mudança em curso. 
Figura 2: peso relativo da redução do gerúndio quanto à faixa etária.

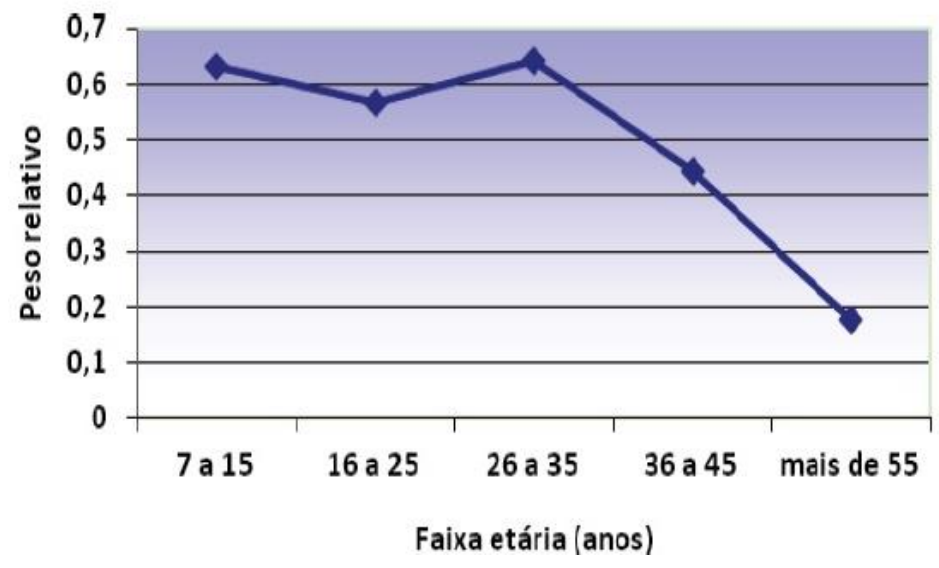

Fonte: Ferreira, Tenani e Gonçalves (2012).

Quanto à escolaridade, constatou-se uma regra de aplicação do apagamento inversamente proporcional: quanto maior a escolarização, menor a tendência de apagamento do /d/ (figura 3). A taxa de apagamento foi maior entre as faixas etárias mais baixas, entre indivíduos de menor escolaridade e entre homens. $\mathrm{O}$ peso relativo para a redução entre falantes desse gênero foi de 0.59 , enquanto que para as mulheres, de 0.40.

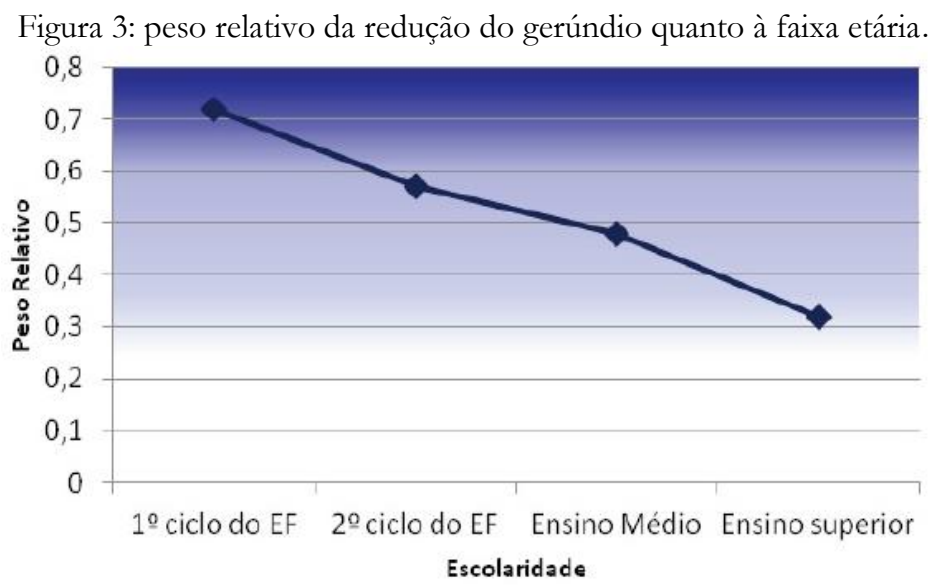

Fonte: Ferreira, Tenani e Gonçalves (2012).

Levando-se em consideração que as premissas clássicas foram confirmadas no referido estudo - homens e informantes com menor nível de escolarização tendem a utilizar variantes estigmatizadas, enquanto que mulheres e informantes com maior nível de escolarização tendem a utilizar variantes de maior prestígio -, os autores afirmam que "o apagamento do [d] em morfema de gerúndio é uma forma socialmente estigmatizada na comunidade de fala" (FERREIRA; TENANI; GONÇALVES, 2012, p. 186).

Especificamente em relação à comunidade alvo do presente estudo, Freitag, Cardoso e Pinheiro (no prelo) analisaram a preservação do /d/ no falar de Aracaju, em contextos/ndo/ em 20 entrevistas sociolinguísticas pertencentes ao Banco de Dados Falares Sergipanos (FREITAG, 2013), estratificadas quanto a fatores sociais: sexo/gênero e escolarização em curso (ensino médio ou superior); fatores linguísticos: classe, extensão da 
palavra, contexto antecedente, contexto seguinte, recorrência da palavra; e fatores estilísticos: tipo de texto e tópico temático.

Os resultados apontaram uma taxa global de conservação do /d/ de 40\%; as mulheres (49\%) e os estudantes do ensino superior (49\%) foram quem mais mantiveram a oclusiva / d/ nos contextos / ndo/. Quanto às variáveis linguísticas, classe da palavra ( $\mathrm{p}>$ 0.0001), contexto anterior $(p>0.0001)$, recorrência da palavra $(p>0.0001)$ e extensão da palavra $(p>0.0001)$ mostraram-se como favorecedores da manutenção (figura 4).

$/ \mathrm{d} / \mathrm{:}$

Os resultados sugerem uma hierarquia dos fatores que favorecem a conservação do

- maior conservação em palavras de outras classes do que em morfemas de gerúndio, o que reforça a existência de parâmetros lexicais para a difusão da mudança;

- a classe da palavra, uma vez que os percentuais de manutenção do /d/ são: numeral $(71 \%)>$ verbo flexionado $(65 \%)>$ nome $(56 \%)>$ conectivo $(48 \%)>$ gerúndio $(33 \%)$;

- maior conservação na fala de estudantes do ensino superior do que do ensino médio, sugerindo que há efeito de monitoramento;

- maior conservação na fala de estudantes, independentemente do nível, do sexo/gênero feminino, demonstrando que o apagamento pode ser alvo de avaliação social negativa, ainda que esteja abaixo do nível da consciência social, à medida que há evidências de que este fenômeno passa também para a leitura, uma situação de maior formalidade e monitoramento (FREITAG et al., no prelo).

O resultado do controle das variáveis estilísticas sugere que a manutenção do /d/ sofre efeitos de monitoramento, pois a taxa de conservação é maior em textos opinativos $(45 \%)$ e em assuntos de maior formalidade (42\%).

Considerando que mulheres (49\%) e indivíduos com maior nível de escolaridade (49\%), em contextos de fala mais monitorados, tendem a preservar o sufixo / ndo/ na fala, Freitag, Cardoso e Pinheiro (no prelo) sugeriram que o apagamento do /d/ se configura como um marcador sensível ao contexto de formalidade, nos termos de Labov (1972).

A ocorrência do apagamento está sujeita ao tipo de realização linguística, que pode ocorrer com maior ou menor grau de monitoramento (ARAÚJO; ARAGÃO, 2016, p. 8), influenciando o apagamento ou manutenção do /d/ em contexto /ndo/.

\section{Metodologia}

Para a análise do apagamento de /d/ no segmento /ndo/, faz-se uso de um corpus constituído por uma amostra de leitura coletada com 20 estudantes: 10 do ensino médio e 10 do superior. $\mathrm{Na}$ ocasião da coleta de dados, os alunos, na presença do pesquisador, realizaram a leitura e simultânea gravação do texto exposto a seguir, escrito especialmente para a realização deste estudo:

"Mudar-se para uma nova cidade pode ser uma experiência desafiadora", diz Fernando, ao relembrar os momentos iniciais de sua chegada à 
Aracaju, quando sair sozinho era um desafio por não conhecer a capital sergipana.

O jovem vive em Aracaju há pouco mais de 6 meses. Estudando na Universidade Federal de Sergipe, no curso de Direito, ainda conhece pouco a cidade. Entretanto, quando tem uma folga, aos finais de semana, tenta ir à Orla de Atalaia. "Estou planejando uma visita ao Museu da Gente Sergipana, dizem que é bem legal para conhecer a cultura do estado", afirma o jovem.

Sonhando em viver novas experiências e adquirir formação na área de Direito e, além disso, contando com o apoio dos pais, Fernando decidiu sair de seu lugar de origem. "Não me arrependo, preciso me arriscar, me jogar no mundo", diz ele, ponderando sobre sua nova vida. "Até agora está valendo a pena".

No texto exposto, há ocorrência de nomes, conectivos e verbos com o segmento /ndo/, a saber: Fernando, quando, vindo, estudando, planejando, sonhando, contando, arrependo, mundo e valendo. As realizações foram controladas quanto às variáveis sociais (sexo/gênero, escolaridade) e linguísticas (contexto posterior, extensão, classe de palavra e conjugação verbal), conforme o estudo realizado por Freitag, Cardoso e Pinheiro (no prelo).

Quanto ao processamento dos dados do corpus, primeiro foi realizada a transcrição das leituras com o software ELAN (BRUGMAN; RUSSEL, 2004). Para as análises prosódicas, foi utilizado o programa PRAAT 5.1.31 (BOERSMA; WEENINK, 2009), por meio do qual as funções demarcadas ou de segmentação (phrasing) e as de proeminência (prominence), com ênfase na curva ou contorno da frequência fundamental, foram especificadas. Depois de identificadas as ocorrências e codificadas, realizou-se a verificação e descrição das frequências e testes de significância (qui-quadrado) (R CORE TEAM, 2018).

\section{Resultados e discussões}

O apagamento do /d/ no segmento /ndo/ sofre influência da diminuição de energia acústica, que sugere menor força articulatória após a realização da sílaba tônica, conforme evidenciado pela análise acústica do fenômeno em questão.

A sílaba tônica apresenta uma corrente de ar expiatória mais forte em relação às não acentuadas ou átonas. Desta forma, a vogal acentuada tende a possuir uma duração mais longa (CRISTÓFARO-SILVA, 2015) e as átonas, por sua vez, mais curtas, devido à perda na força de elocução.

As figuras 4 e 5 exemplificam, respectivamente, a manutenção e o apagamento da oclusiva /d/. Ao comparar a curva ou contorno da frequência fundamental ${ }^{3}$ nos excertos ${ }^{4}$, identifica-se a diferença da proeminência acústica entre as realizações planejando e planejano:

\footnotetext{
3 “O parâmetro físico que controla direta e primariamente a sensação de pitch é a frequência fundamental, isto é, o correlato acústico da frequência de vibração das cordas vocais, os estudos fonéticos da entoação privilegiam a análise da curva de frequência fundamental ao longo dos enunciados" (BARBOSA, 2012, p. 20). ${ }_{4}$ Devido à qualidade dos áudios e as gravações terem sido realizadas em uma sala de aula, não foram analisados os traços de pitch, duração e formantes.
} 
Figura 4: frequência fundamental do contexto /ndo/ com apagamento do /d/. Informante 1: (Estou planejando uma visita ao museu da Gente Sergipana).

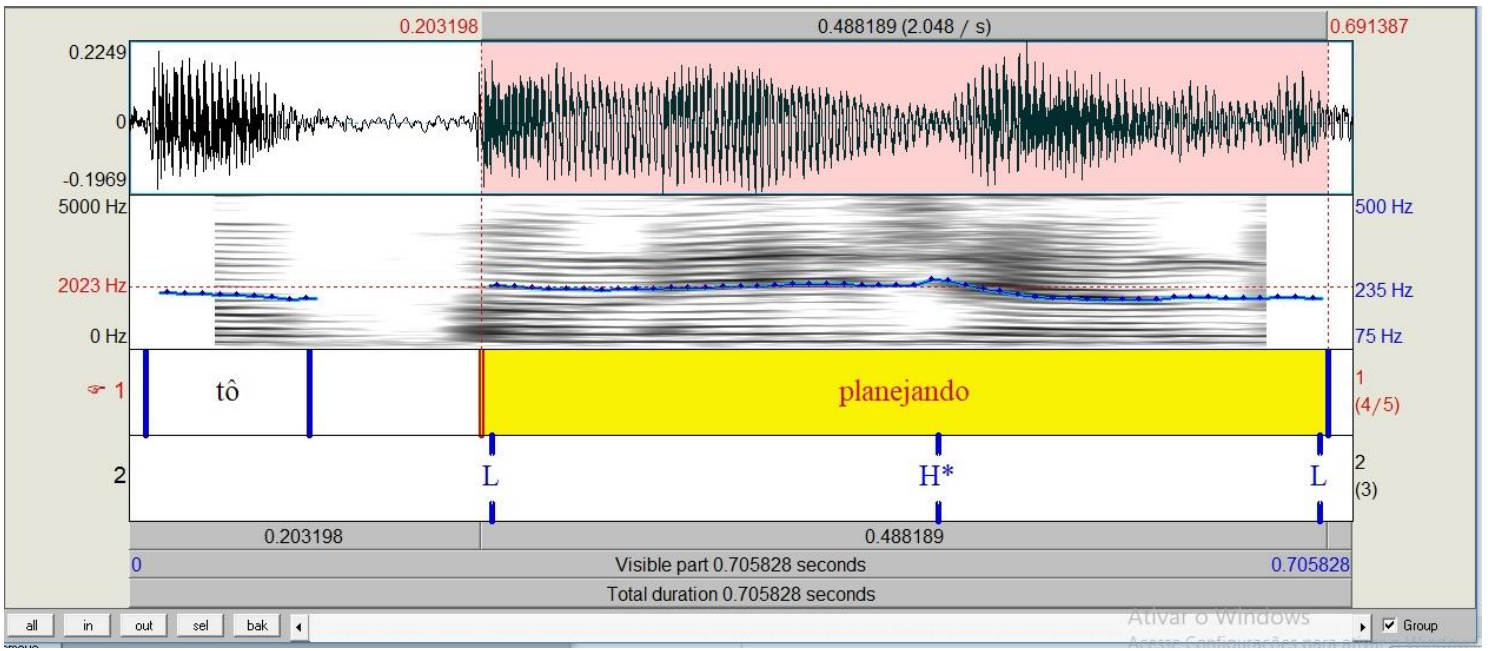

Figura 5: frequência fundamental do contexto /ndo/. Informante 1: (Estou planejano uma visita ao museu da Gente Sergipana).

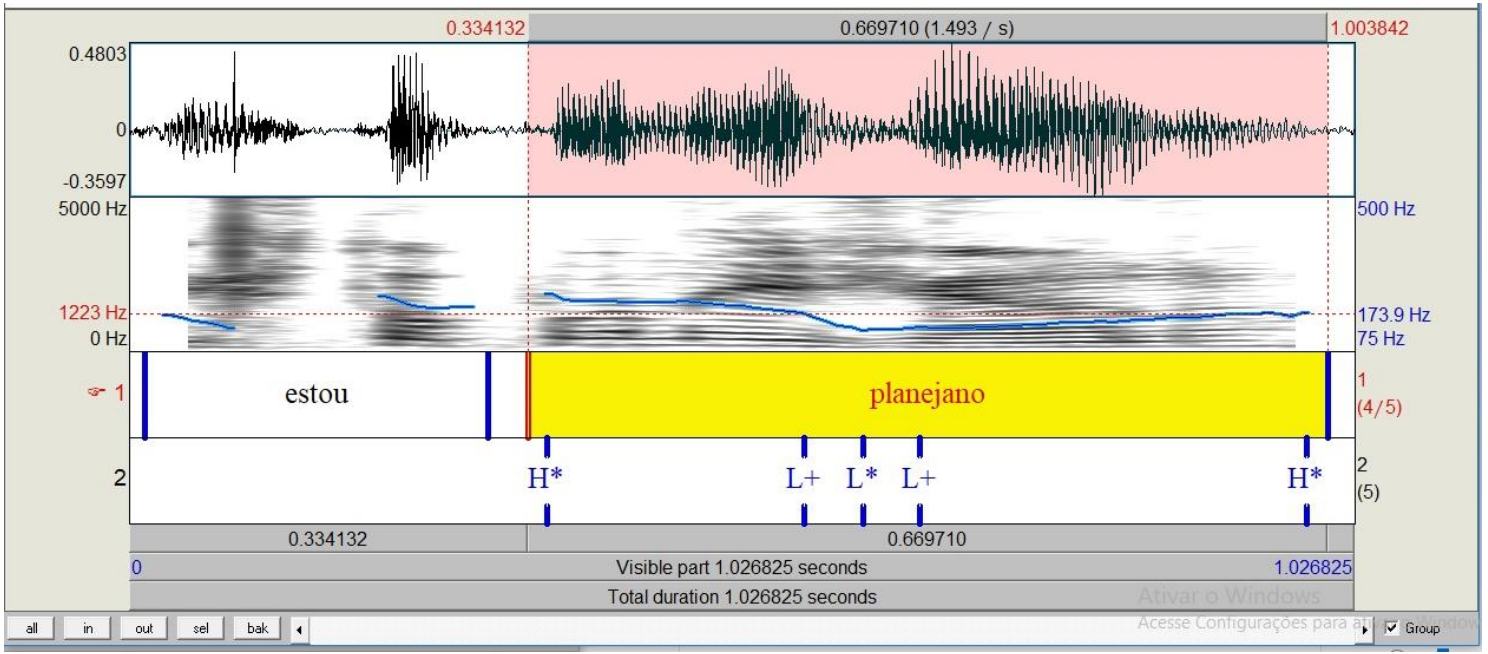

Percebe-se, a partir dos excertos destacados, que na realização estou planejano houve queda na proeminência acentual, demonstrada pelos pitch accents, "estes analisados à luz da teoria métrica-autosegmental apenas como sequências ou combinações de tons altos e baixos, sendo representados por meio dos rótulos H (high) e L (low), e pela combinação destes" (LUCENTE, 2017, p. 14).

A figura 5 demonstra a descida da frequência fundamental na realização de planejano. Isto ocorre porque, após a realização da sílaba tônica, há diminuição da energia acústica. O apagamento do /d/, neste caso, acontece por consequência da função demarcativa que o falante assinala para estruturar os limites de constituintes prosódicos, como nas sílabas, palavras fonológicas ou grupos acentuais (BARBOSA, 2012). Isso significa que o falante assinala a fronteira prosódica a partir da força fonológica na constituição da palavra.

\footnotetext{
${ }^{5}$ No fragmento em que o apagamento é demonstrado (figura $\mathrm{x}$ ), $\mathrm{L}^{*}$ simboliza a descida abrupta que acontece na realização fonética do informante.
} 
Existe uma relação sintagmática nas primeiras sílabas das palavras (planejano/planejando): elas têm mais energia e maiores valores de frequência fundamental, enquanto as últimas sílabas, devido ao apagamento do /d/, sofrem uma oposição paradigmática, ou seja, com o apagamento, o final da palavra é afetado prosodicamente. Esta constatação pode ser observada no estudo de Ferreira, Tenani e Gonçalves (2012, p. 173), no qual os autores realizaram uma análise acústica a partir da percepção que os falantes têm do apagamento da oclusiva /d/. Constata-se que "a percepção do apagamento do morfema de gerúndio está relacionada a uma perda de qualidade da consoante /d/".

As figuras 6 e 7 exemplificam ocorrências em que não há diferença na queda da proeminência do segmento /ndo/:

Figura 6: frequência fundamental o contexto /ndo/. Informante 4: (ao relembrar os momentos iniciais de sua chegada à Aracaju, quando sair era um desafio).

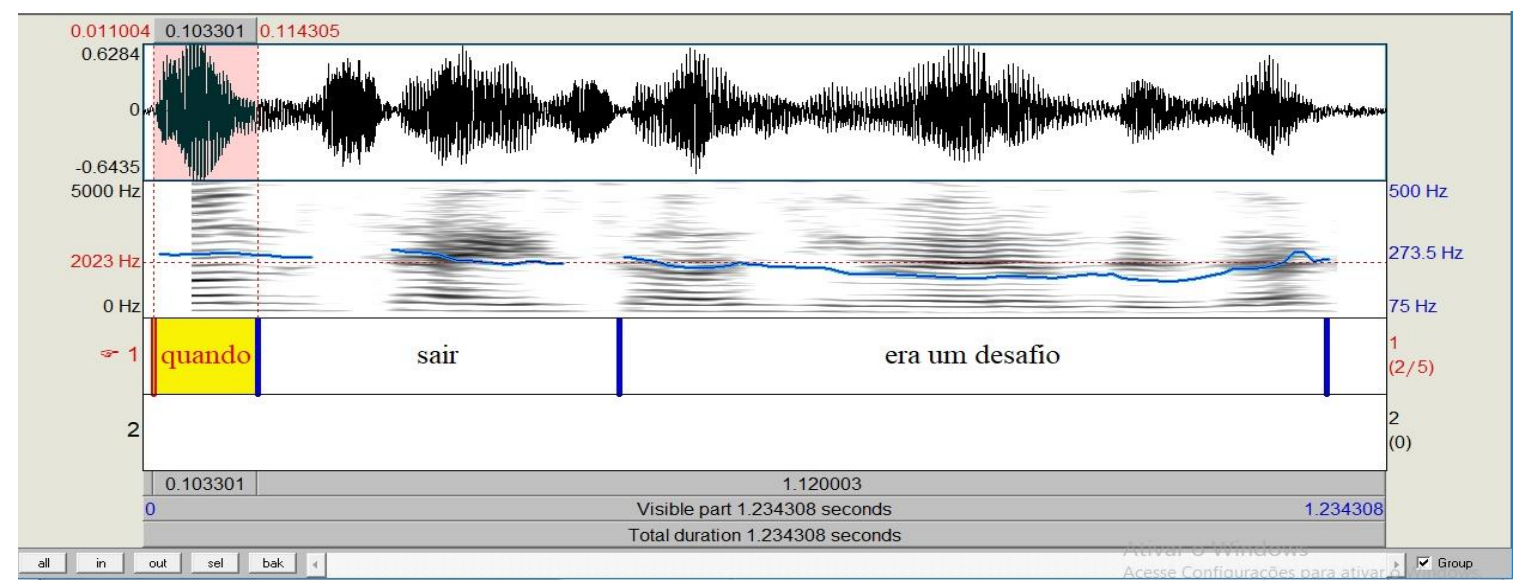

Figura 7: frequência fundamental do contexto /ndo/ com apagamento do /d/. Informante 1: (ao relembrar os momentos iniciais de sua chegada à Aracaju, quando sair era um desafio).

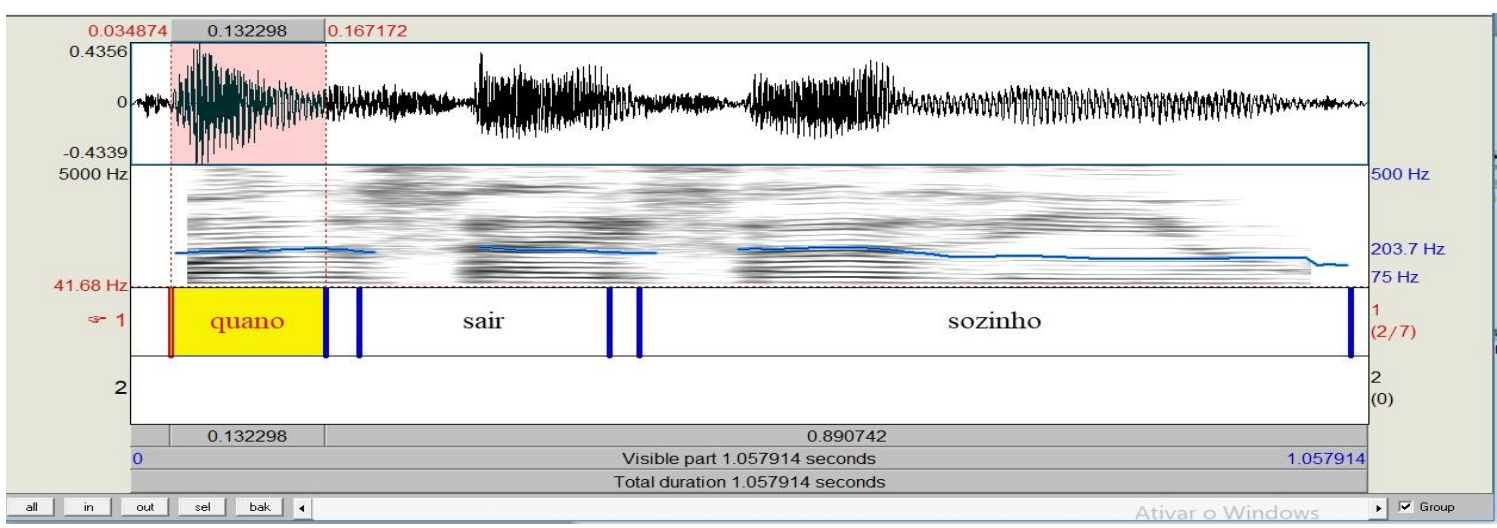

Observa-se que, nas ocorrências quando e quando, o pico da curva se encontra após a sílaba tônica, o que faz com que tais vocábulos não sejam proeminentes para os ouvintes, porque "são relevantes para um falante do português brasileiro apenas os movimentos singulares que se passam durante as sílabas tônicas das palavras fonológicas" (BARBOSA, 2012, p. 18).

Este fato sugere o porquê do fenômeno do apagamento ser tão difícil de ser detectado em uma situação de oitiva, sendo, muitas vezes, despercebido na fala. Os pontos 
que se assemelham nos contornos demonstram um correlato da queda de proeminência que acontece no final das palavras. Neste caso, o correlato entre o apagamento ou não da oclusiva dental /d/ está relacionado à força articulatória das palavras no começo da unidade entoacional e não no fim, logo "são reservados às sílabas portadoras de proeminência prosódica" (SCARPA; SVARTSMAN, 2012, p. 29). Por isso, o apagamento não ocorre nos trechos nucleares, mas sim nos periféricos e fronteiriços (como em palavras que apresentam o segmento /ndo/ e não perdem o /d/, como condominio).

A perda de qualidade do segmento /d/ influencia a manutenção ou o apagamento da oclusiva dental em contexto /ndo/. A fim de descrever esse fenômeno na atividade de leitura, realiza-se uma análise variacionista, na qual são controladas variáveis linguísticas (contexto posterior, extensão, classe de palavra e conjugação verbal) e sociais (sexo/gênero, escolaridade), cujos resultados são apresentados a seguir.

Figura 8: realização da oclusiva /d/ em contextos /ndo/ na leitura em voz alta.
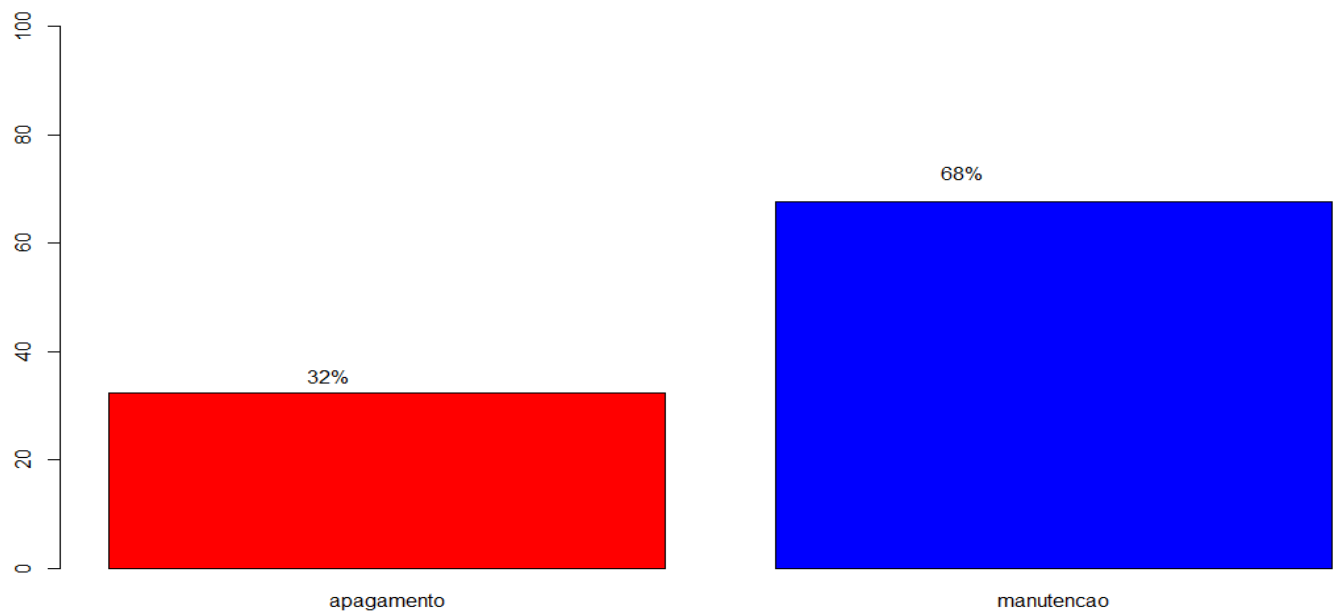

Das 260 realizações do segmento / ndo/ presentes no corpus utilizado neste trabalho, 176 preservaram a oclusiva, o que equivale a uma taxa de apagamento de $32 \%$ (figura 8), superior à taxa encontrada na amostra de fala da mesma comunidade, que foi de 60\% (FREITAG; CARDOSO; PINHEIRO, no prelo). Isto sugere que a leitura apresenta maior monitoramento do que a fala, reforçando o traço de marcador estilístico associado ao fenômeno. Almeida e Oliveira (2017), a partir de dados de entrevistas, constataram, no falar de Alagoas, uma taxa de apagamento de 42\%. Na Paraíba, essa mesma taxa foi de 37,7\% (LUCENA; VASCONCELOS, 2007), também na fala. Araújo e Aragão (2016), por sua vez, a partir do uso dos questionários do AliB, encontram uma taxa de apagamento nas capitais nordestinas de 22,90\%.

Estatisticamente, não há, no apagamento do /d/ em segmento /ndo/, significância $(\mathrm{p}=5.928 \mathrm{e}-06)$ da variável contexto posterior, conforme exposto (figura 9). 
Figura 9: distribuição do apagamento quanto ao contexto posterior.

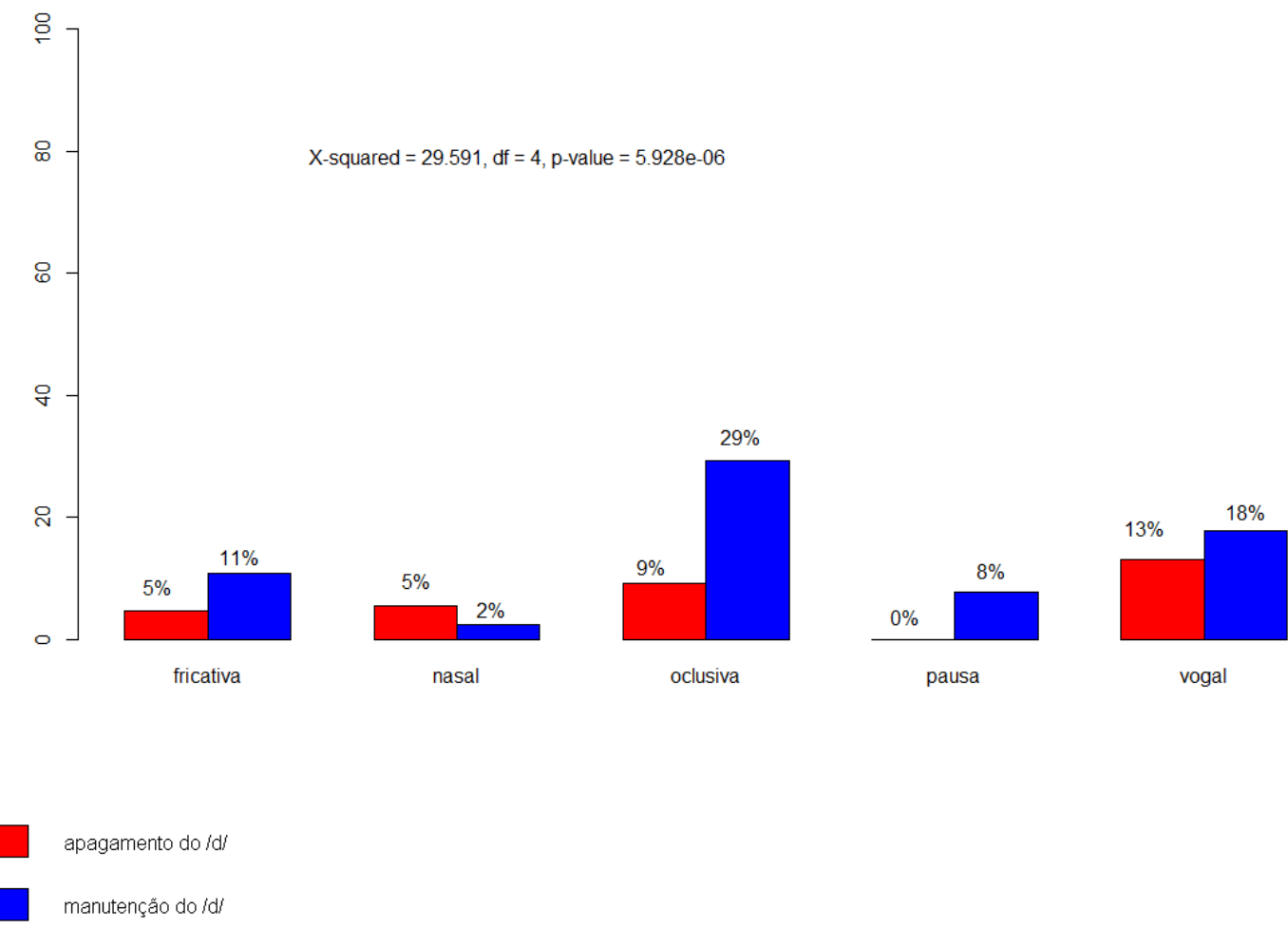

Apesar da não relevância, é possível observar que os ambientes que favorecem a manutenção do /d/ são os que há oclusiva $(29 \%)>\operatorname{vogal}(18 \%)>$ fricativa $(11 \%)>$ pausa $(8 \%)>\operatorname{nasal}(2 \%)$.

No que tange ao favorecimento do apagamento da oclusiva /d/, observa-se que os resultados desta pesquisa seguem o direcional evidenciado por Martins (2004), para quem o som nasal, realizado após o segmento /ndo/, favorece o apagamento. Nas realizações feitas pelos participantes deste estudo, o contexto posterior foi quem menos favoreceu a manutenção da consoante /d/.

A variável extensão da sílaba se mostrou estatisticamente significativa $(\mathrm{p}=0.03331)$ para a realização ao apagamento de /d/ na leitura, conforme exposto (figura 10). 
Figura 10: distribuição do apagamento quanto à extensão da palavra na leitura.
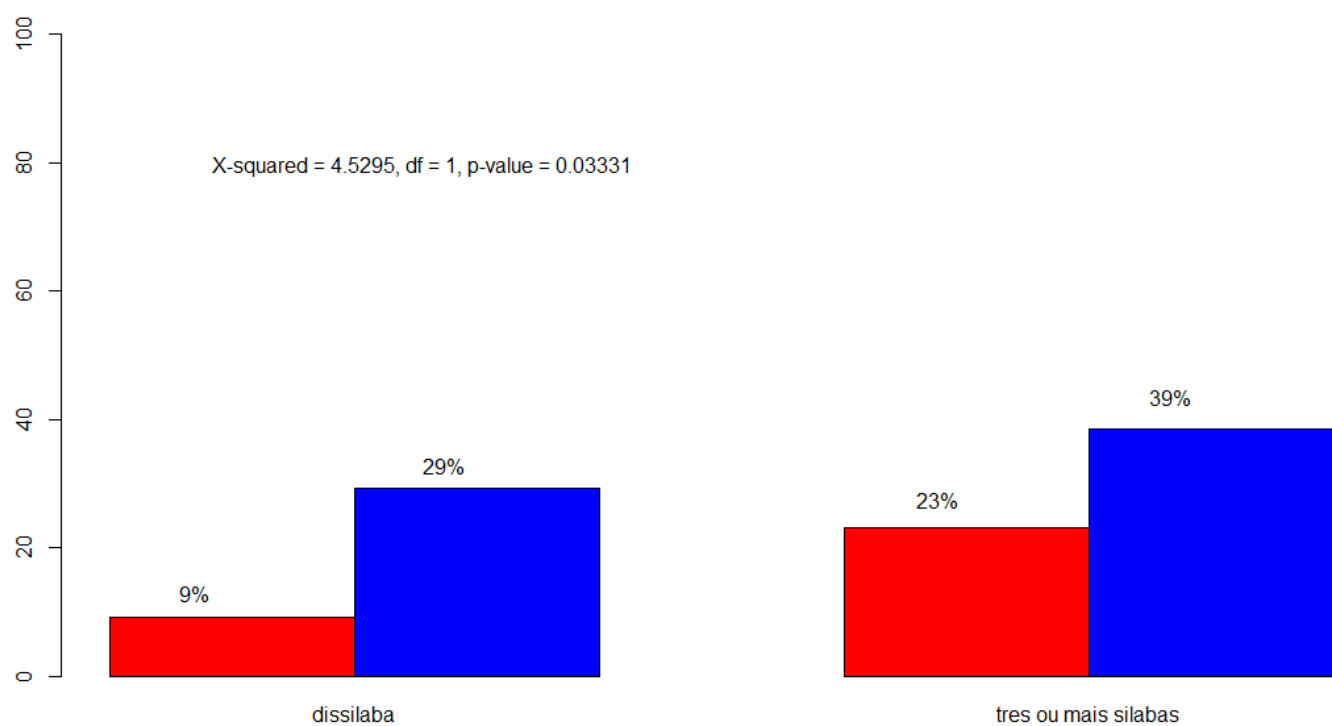

apagamento do /d/

manutençắo do /d

Os resultados sugerem que o apagamento do /d/ na leitura tem maior ocorrência entre palavras de três ou mais sílabas (23\%). Freitag, Cardoso e Pinheiro (no prelo) apontam que, no falar dessa mesma comunidade, a preservação do /d/ no segmento /ndo/ também é menor entre palavras trissílabas (35\%) e polissílabas (25\%). O mesmo direcional de apagamento da oclusiva /d/ em relação à extensão da palavra foi constatado no falar de Alagoas, por Almeida e Oliveira (2017): o percentual de apagamento nas palavras polissílabas foi de 51,4\%; enquanto nas dissílabas, de $29,6 \%$.

De acordo com Mollica e Mattos (1992), o apagamento em palavras de maior extensão silábica pode ser explicado levando-se

em consideração fatores de processamento que atuam no nível da unidade da palavra: os segmentos tendem à não realização, quando as cadeias vocabulares são grandes. Note-se que esse não é um fator de natureza estritamente fonética mas, antes, de caráter psicolinguístico. (MOLLICA; MATOS, 1992, p. 56).

Assumimos, portanto, que, assim como acontece na fala, no momento da leitura oral, à medida que o leitor lê enunciados muito longos, ele favorece a perda de segmentos fônicos.

A classe da palavra não foi estatisticamente significativa na amostra analisada no presente trabalho $(\mathrm{p}=0.1787)$. Todavia, é importante considerar que, assim como na fala, o apagamento do /d/ em contextos / ndo/ na leitura teve maior ocorrência entre verbos $(22 \%)>$ nomes $(5 \%)$ e conectivos $(5 \%)$, conforme exposto na figura 11. 
Figura 11: distribuição do apagamento quanto à classe de palavra.

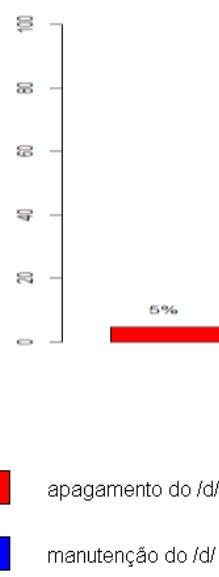

Há uma diferença significativa entre o percentual de apagamento entre verbos e outras categorias. Cumpre destacar que, na amostra utilizada, todos os verbos estavam na forma de gerúndio. Para Mollica e Mattos (1992, p. 58), o apagamento do /d/ entre as formas verbais de gerúndio "poderia ser explicado pelo fato de / ndo/ não fazer parte do radical do verbo, mas ser a ele afixado. Note-se que /d/, sendo parte da raiz, como em nomes, conjunções ou verbos no presente, tende a resistir mais fortemente à queda, pois se acha na unidade base (raiz) do vocábulo”. Na mesma direção vão os resultados de Lucena e Vasconcelos (2007), cuja taxa de manutenção do /d/ entre conjunções e substantivos foi de $98,5 \%$.

Levando-se em consideração os resultados expostos acima, destaca-se o apagamento do /d/ no segmento / ndo/ entre os verbos das três conjugações presentes no corpus de análise. Nesta perspectiva, a conjugação verbal foi estatisticamente significativa $(\mathrm{p}=0.002697)$ :

Figura 12: distribuição do apagamento quanto à conjugação verbal.

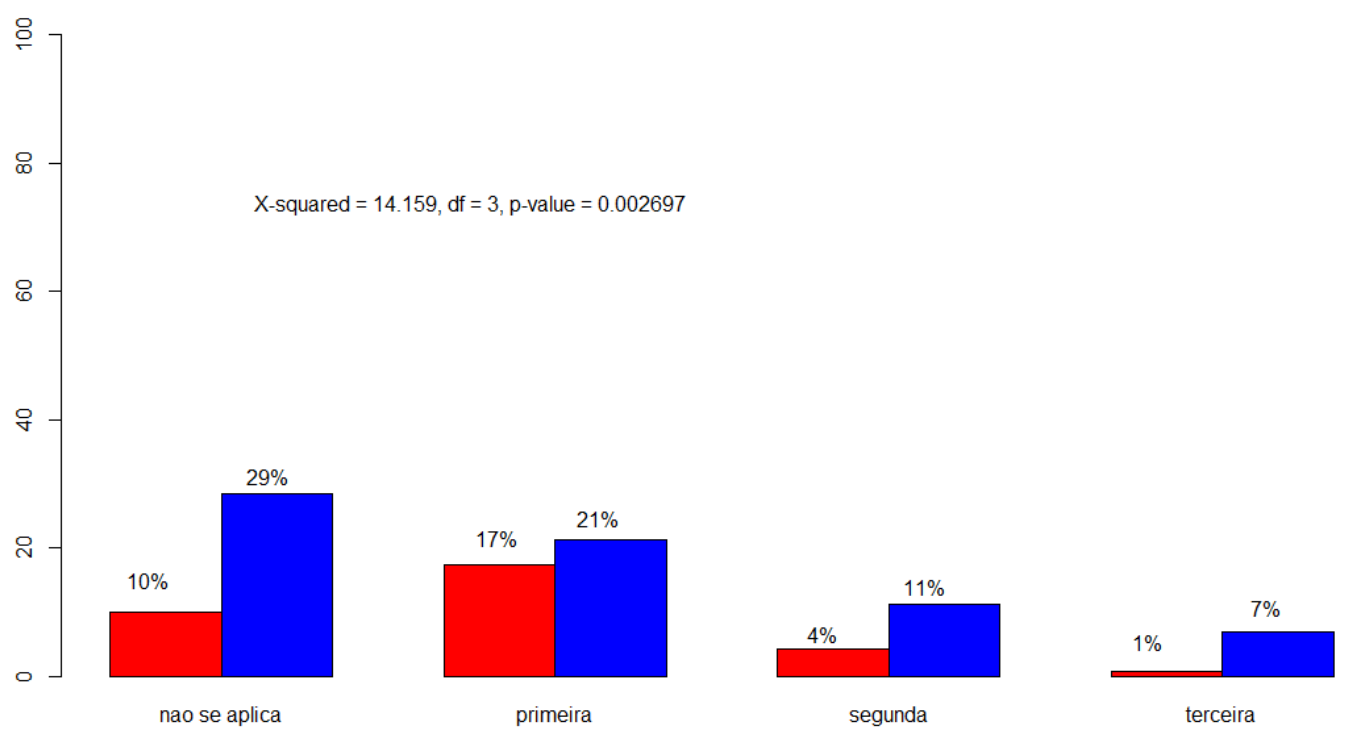


apagamento do /d $/$

manutenção do /d/

A figura 12 expressa os percentuais de ocorrência de manutenção e apagamento entre nomes, conectivos (classes dentre as quais a categorização em conjugações não se aplica) e verbos de primeira, segunda e terceira conjugação.

Os verbos de primeira conjugação: estudando, planejando, sonhando, contando, foram os que mais sofreram apagamento da oclusiva /d/ (45/100), apresentando um percentual de $(17 \%)$; seguidos pelos de segunda $(11 / 40)$ e terceira $(2 / 20)$, com percentuais de $(4 \%)$ e $(1 \%)$, respectivamente. Nota-se que a diferença entre o percentual apresentado pelos de segunda (arrependo, valendo) e de terceira (vir) foi alta.

O maior percentual de apagamento entre verbos da primeira conjugação pode ser explicado a partir da vogal temática dessa categoria lexical. Os verbos de primeira e segunda conjugação, cujas vogais temáticas são /e/ e /a/, média baixa e baixa central, respectivamente, foram os que apresentaram maior percentual de apagamento do /d/ no segmento /ndo/. Resultado semelhante foi obtido no estudo realizado por Nascimento, Araújo e Carvalho (2013) e Vieira (2011), para quem as vogais /e/ e /a/, em contexto antecedente a verbo no gerúndio, favoreceram o apagamento.

Do ponto de vista social, as variáveis sexo/gênero e escolaridade não foram estatisticamente significativas, conforme exposto nas figuras 13 e 14 .

Figura 13: distribuição do apagamento quanto ao sexo/gênero.
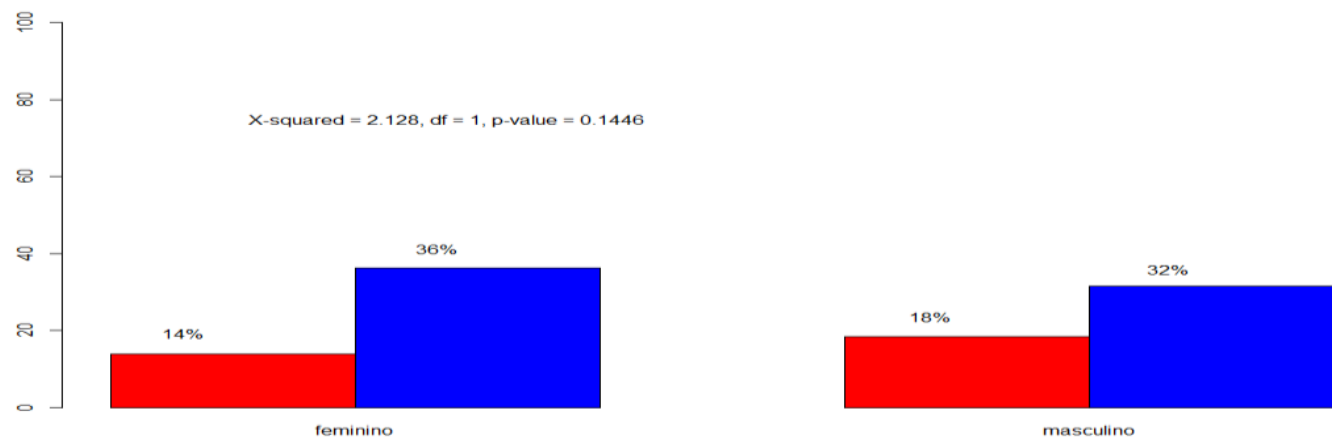

apagamento do $/ \mathrm{d} /$

manutençẫo do /d/

$\mathrm{Na}$ leitura, o apagamento da consoante / d/ em contexto / ndo/ entre homens e mulheres não foi estatisticamente significativa $(p=0.1446)$. O percentual de ocorrência desse fenômeno entre mulheres foi de $42 \%$, enquanto entre homens, de $57 \%$.

$\mathrm{Na}$ fala espontânea dessa mesma comunidade, pelo contrário, essa variável foi estatisticamente significativa ( $\mathrm{p}>0,0001$ ): enquanto o percentual de apagamento entre mulheres foi de 51\%, entre os homens, foi de 68\% (FREITAG; CARDOSO; PINHEIRO, no prelo). 
Tais resultados sugerem, portanto, que a premissa básica de que os homens são quem menos utilizam a variável padrão, evidenciada em estudos na fala (LUCENA; VASCONCELOS, 2007; FERREIRA; TENANI; GONÇALVES, 2012; entre outros), não tem a mesma aplicação em situações de maior monitoramento, uma vez que a diferença entre os percentuais de apagamento entre homens e mulheres é pequena.

Figura 14: distribuição do apagamento quanto à escolaridade.
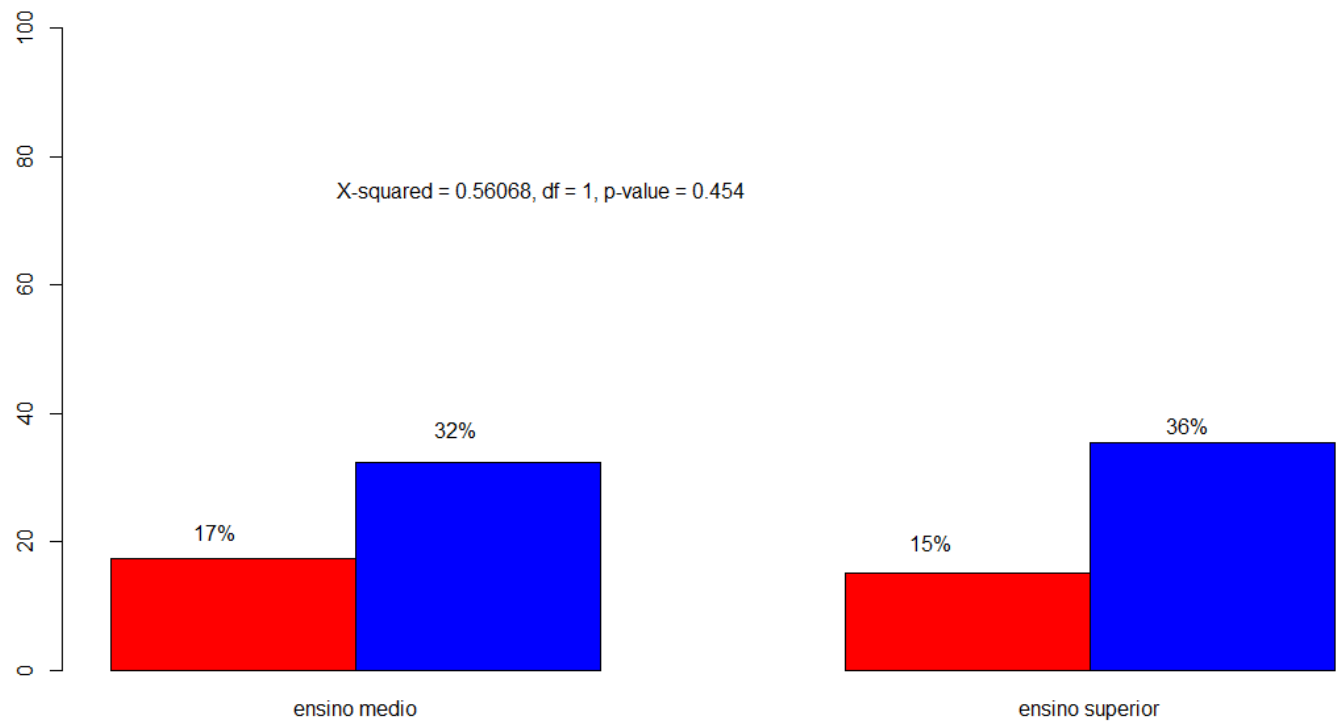

apagamento do /d/

manutençăo do /d/

Na leitura, a variável escolaridade não se mostrou estatisticamente significativa $(\mathrm{p}=$ 0.454). Os percentuais de apagamento da consoante /d/ entre estudantes do ensino médio e superior foram, respectivamente, $17 \%$ e $15 \%$. Na fala espontânea dos estudantes dessa mesma comunidade, pelo contrário, a diferença entre os níveis de escolaridade foi mais expressiva: enquanto o percentual de preservação do /d/ entre estudantes do ensino médio foi de 30\%, entre os do ensino superior foi de 60\% (FREITAG; CARDOSO; PINHEIRO, no prelo).

O menor percentual de apagamento na leitura sugere que essa atividade, por ser mais monitorada, não favorece o apagamento do /d/ no segmento /ndo/. Esse fenômeno parece se comportar como um marcador sociolinguístico sensível ao contexto de formalidade. Ainda que recorrente na fala (NASCIMENTO; ARAÚJO; CARVALHO, 2013; FERREIRA; TENANI; GONÇALVES, 2012), na leitura esse fenômeno tende a ser desfavorecido.

\section{Considerações finais}

A distribuição do apagamento do / $\mathrm{d} /$ evidencia a necessidade de estudos acerca da saliência - que pode ser consciente ou inconsciente - da redução do /ndo/. O percentual 
de manutenção da referida consoante fornece pistas da influência do monitoramento estilístico: a ocorrência do segmento /ndo/ é maior em contextos de leitura que de fala. Os resultados obtidos sugerem que, ainda que o apagamento do /d/ seja recorrente na fala há, na situação de leitura, restrição.

Assume-se que o monitoramento característico à situação de leitura é responsável pela não-relevância estatística das variáveis gênero e escolaridade, que possuem significativa influência na variação / cantando/ > / cantano/ em estudos anteriores (LUCENA; VASCONCELOS, 2007; ALMEIDA; OLIVEIRA, 2017; entre outros), que sugerem que as mulheres com maior nível de escolaridade tendem a não realizar o apagamento do /d/.

Quanto ao aspecto sociocognitivo, fica evidente também a necessidade de estudos acerca da percepção da ocorrência ou não do apagamento do /d/, uma vez que as análises prosódicas mostraram que há perda das propriedades prosódicas da sílaba, o que pode fazer com que o falante deixe de perceber a ausência da referida consoante no segmento /ndo/.

\section{Referências}

ALMEIDA, A. N. S.; OLIVEIRA, A. J. Você fala cantano? Uma análise do apagamento em /d/ em gerúndios no falar de Maceió/AL. Letrônica, v. 10, p. 200-209, 2017.

ARAÚJO, A. A.; ARAGÃO, M. S. S. Uma fotografia sociolinguística da redução do gerúndio com base nos dados do Atlas Linguístico do Brasil. Revista (Con) textos Linguísticos, v. 10, n. 16, p. 8-23, 2016.

BARBOSA, P. A. Conhecendo melhor a prosódia: aspectos teóricos e metodológicos daquilo que molda nossa enunciação. Revista Estudos da Linguagem, Belo Horizonte, v. 20, n. 1, p. 11-27, 2012.

BOERSMA, P.; WEENINK, D. Praat: doing phonetics by computer (Versão 5.1.15) [Programa de computador], 30 ago. 2009. Disponível em: www.praat.org. Acesso em: 2 out. 2018.

BORTONI-RICARDO, Stella Maris. Educação em língua materna: a sociolinguística na sala de aula. São Paulo: Parábola Editorial, 2004.

BRUGMAN, H.; RUSSEL, A. Annotating Multimedia/Multi-modal resources with ELAN. In: Proceedings of LREC 2004, Fourth International Conference on Language

Resources and Evaluation, 2004.

COLTHEART, M. Modelando a leitura: a abordagem da dupla rota. In: SNOWLING, M. J.; HULME, C. (org.). A ciência da leitura. Porto Alegre: Penso, 2013, p. 24-41.

CRISTÓFARO-SILVA, T. Fonética e fonologia do português: roteiro de estudos e guia de exercícios. 10 ed. São Paulo: Contexto, 2015. 
FERREIRA, J. S.; TENANI, L. E.; GONÇALVES, S. C. L.. O morfema do gerúndio "ndo" no Português Brasileiro: análise fonológica e sociolinguística. Revista Letras \& Letras, Uberlândia, v. 28, n. 1, p. 167-188, 2012.

FREITAG, Raquel Meister Ko. Banco de dados falares sergipanos. Working Papers em Linguística, v. 14, n. 2, p. 156-164, 2013.

FREITAG, R.; CARDOSO, P. B.; PINHEIRO, B. M. Saliência na conservação de /d/ no segmento /ndo/: efeitos sociais e estilísticos. Gragoatá, v. 23, n. 46, p. 654-678, 2018.

HORA, D.; AQUINO, M. Da fala para a leitura: análise variacionista. Revista Alfa, v. 56, n. 3, p. 1099-1115, 2012.

LABOV, W. Sociolinguistics patterns. Philadelphia: University of Pennsylvania, 1972.

LABOV, W.; BAKER, B. What is a reading error? Manuscrito não publicado, 2003.

Disponível em: https://www.ling.upenn.edu/ wlabov/Papers/WRE.html. Acesso em: 2 out. 2018.

LUCENA, R. M.; VASCONCELOS, D. C. Apagamento da oclusiva dental no dialeto do Brejo paraibano: uma regra variável. A Cor das Letras, Feira de Santana, v. 8, n. 1, p. 231 240, 2007.

LUCENTE, L. Introdução à análise entoacional. In: FREITAG, R. M. K.; LUCENTE, L. (org). Prosódia da fala: pesquisa e ensino. São Paulo: Blucher, 2017.

MACHADO, Alessandra Pereira Gomes. Variação linguística e leitura: fenômenos variáveis da fala na leitura em voz alta. A Cor das Letras, v. 19, n. 4, p. 196-218, 2018.

MARTINS, I. F. M. Apagamento da oclusiva dental /d/: perspectivas variacionistas e fonológicas. In: HORA, D. (org.). Estudos sociolinguísticos: perfil de uma comunidade. Santa Maria: Pallotti, 2004, p. 55-82.

MOLLICA, Maria Cecília. Influência da fala na alfabetização. Rio de Janeiro: Tempo Brasileiro, 1998.

MOLLICA, M. C. M.; MATTTOS, P. B. Pela conjugação das abordagens variacionista e difusionista. Revista Estudos Linguísticos, v. 1, n. 1, p. 53-64, 1992.

NASCIMENTO, K. R. S; ARAÚJO, A. A.; CARVALHO, W. J. A redução do gerúndio no falar popular de Fortaleza: um olhar variacionista. Veredas, v. 2, p. 398-413, 2013.

R CORE TEAM. R: A language and environment for statistical computing. Viena, $\mathrm{R}$ Foundation for Statistical Computing, 2018.

SCARPA, E; SVARTSMAN, F. F. A estrutura prosódica das disfluências em português brasileiro. Cadernos de Estudos Linguísticos, Campinas, v. 54, n. 1, p. 25-40, jan./jun. 2012.

VIEIRA, Marília Silva. Apagamento de /d/: abordagem sociolinguística sob a perspectiva do gênero sexual. Web-Revista Sociodialeto, v. 1, n. 4, p. 1-27, 2011. 